\title{
Urinary $\mathrm{N}$-acetyl- $\beta$-D-glucosaminidase in epileptic children treated with antiepileptic drugs
}

\author{
L Csáthy, A V Oláh, B Clemens, I György, J Varga
}

\begin{abstract}
Aim-To investigate the effect of prolonged use of antiepileptic drugs on renal function in children.

Methods-Prospective study of 72 children (aged 3-18 years) with epilepsy, on either monotherapy $(n=44)$ or combined therapy $(n=28)$. The length of treatment varied from 1 to 13 years. Drugs used were valproic acid, carbamazepine, ethosuximide, clonazepam, clobazepam, and vigabatrin.

Results-In 65 patients plasma concentrations of the drugs were in the therapeutic range. In the remaining seven, plasma concentrations were slightly high. In 33 patients urinary $\mathbf{N}$-acetyl- $\beta$-D-glucosaminidase (NAG) activity was raised. The incidence of pathological NAG indices was significantly higher in the combined therapy group than in the monotherapy group. There were also significant differences in the NAG indices of patients depending on the duration of therapy.

Conclusions-Results suggest that chronic use of some antiepileptic drugs-in spite of normal blood concentrations-may alter tubular function, and the dysfunction may result in clinical symptoms. Therefore, we recommend screening of tubular function in these patients.

(Arch Dis Child 2000;83:420-422)
\end{abstract}

Department of

Paediatrics, County

Teaching Hospital,

H-4043 Debrecen,

Bartók B 2-26,

Hungary

L Csáthy

Department of Neurology, County Teaching Hospital B Clemens

Department of Paediatrics, University of Debrecen, Medical and Health Science Center, Medical

School, Debrecen A V Oláh

I György

Nuclear Medicine Centre, University of Debrecen

J Varga

Correspondence to: Dr Csáthy

lcsathy@mail.datanet.hu

Accepted 13 July 2000
Keywords: $\mathrm{N}$-acetyl- $\beta$-D-glucosaminidase; NAG; tubular function; antiepileptic drugs; nephrotoxicity

Urinary N-acetyl- $\beta$-D-glucosaminidase (NAG; EC 3.2.1.30) is a hydrolytic enzyme with a molecular weight of about 140000 daltons. In humans two isoenzymes ( $\mathrm{A}$ and $\mathrm{B}$ ) are present. The A isoenzyme is present in the lysosomes of proximal tubular cells. On the basis of several clinical trials it has been accepted that a raised amount of the enzyme in urine is a marker of tubular injury. ${ }^{1-4}$ After a long duration of treatment, antiepileptic drugs (AEDs) may cause changes in renal function. Proximal tubular renal syndrome caused by valproic acid has been reported. ${ }^{5}$ Acute interstitial nephritis has been observed after the administration of valproic acid $^{6}$ and carbamazepine. ${ }^{7}$ Acute renal failure has been described as a consequence of carbamazepine, ${ }^{8}$ and nephrotic syndrome after administration of ethosuximide. ${ }^{9}$ Few publications have discussed urinary NAGase as a marker of AED induced renal functional impairment. ${ }^{10-13}$ The aim of this study was to measure urinary excretion of NAGase in children with epilepsy, and assess the effects of AEDs on NAGase activity.

\section{Patients and methods}

Seventy two children aged 3-18 years, who had different epilepsy syndromes (partial simple or complex, generalized seizures, myoclonic epilepsies) were included in the study. The duration of antiepileptic treatment varied from one to 13 years (table 1). Forty four children were on monotherapy, and 28 on combined therapy (table 2). Carbamazepine and valproic acid were administered most frequently, either alone or in combination with other AEDs (clonazepam in seven patients, clobazepam in four, vigabatrin in six, ethosuximide in three; table 3). In 65 patients plasma concentrations of the drugs were in the therapeutic range. In only seven cases were plasma concentrations of the drugs above the therapeutic range (valproic acid $>10 \mu \mathrm{g} / \mathrm{ml}$ in two cases, carbamazepine $>100 \mu \mathrm{g} / \mathrm{ml}$ in five cases). Urine and blood samples were collected on the same day. From the blood sample drawn for determining AED serum concentration, we also determined renal function. The patients did not have any sign of renal dysfunction: urinary creatinine, plasma creatinine, urea, and electrolytes were in the normal range. None had received aminoglycoside treatment since epilepsy was diagnosed. The NAGase determination with VRAGlcNAc substrate has been described and the detailed age dependent normal values and

Table 1 The number of patients and NAGir values depending on duration of therapy

\begin{tabular}{llll}
\hline & \multicolumn{2}{l}{ Length of therapy } \\
\cline { 2 - 4 } & $<5$ years & $5-9$ years & $>10$ years \\
\hline $\begin{array}{l}\text { Number of patients } \\
\text { Number of }\end{array}$ & 35 & 26 & 11 \\
$\quad$ normal/pathological & & & \\
$\quad$ NAGir results & $19 / 16$ & $16 / 10$ & $4 / 7$ \\
Mean of NAGir values & 1.02 & 0.97 & 2.17 \\
SD of values & 0.66 & 0.53 & 1.85 \\
\hline
\end{tabular}

Results analysed by one way analysis of variance, $\mathrm{p}<0.001$.

Table 2 The number of patients and NAGir values depending on type of therapy

\begin{tabular}{lll}
\hline & \multicolumn{2}{c}{ Type of therapy } \\
\cline { 2 - 3 } & Monotherapy & Combined therapy \\
\hline $\begin{array}{ll}\text { Number of patients } \\
\text { Number of pathological }\end{array}$ & 44 & 28 \\
$\quad$ NAGir results & $15(34 \%)^{\star}$ & $18(64 \%)^{\star}$ \\
$\begin{array}{l}\text { Mean of NAGir values } \\
\text { SD of values }\end{array}$ & $0.99 \dagger$ & $1.52 \dagger$ \\
& 0.73 & 1.21
\end{tabular}

${ }^{\star} \mathrm{p}<0.05, \chi^{2}$ test.

$\mathrm{tp}<0.05$, Welch's d test. 
Table 3 Drugs used for treatment and urinary NAGir results of patients receiving monotherapy or combined therapy

\begin{tabular}{llll}
\hline Drug & No. of cases & $\begin{array}{l}\text { Pathological } \\
\text { NAGir }\end{array}$ & $\begin{array}{l}\text { NAGir } \\
\text { (mean }+ \text { SD) }\end{array}$ \\
\hline $\begin{array}{l}\text { Monotherapy } \\
\quad \text { Carbamazepine }\end{array}$ & 23 & 6 & $0.79+0.41^{\star}$ \\
$\quad \begin{array}{l}\text { Valproic acid } \\
\quad \text { Ethosuximide }\end{array}$ & 20 & 9 & $1.23+0.95^{\star}$ \\
Combined therapy & 1 & 0 & 0.70 \\
$\quad$ Carbamazepine + valproic acid & 8 & 3 & $1.31+0.79$ \\
$\quad$ Carbamazepine + other & 9 & 3 & $2.04+1.77$ \\
$\quad$ Valproic acid + other & 11 & 4 & $1.24+0.81$ \\
\hline
\end{tabular}

Results for monotherapy analysed by Welch's $d$ test; ${ }^{\star} p>0.05$.

Results for combined therapy analysed by one way analysis of variance; $\mathrm{p}>0.1$.

Table 4 Urinary NAG index values in healthy newborns and children (mean $+S D)$

\begin{tabular}{llll}
\hline Age $(y)$ & $\begin{array}{l}\text { Number of } \\
\text { patients }\end{array}$ & $\begin{array}{l}\text { Urinary } \\
\text { creatinine } \\
(\text { mmol/l) }\end{array}$ & $\begin{array}{l}\text { NAG index } \\
(\mu m o l / m i n / m m o l \\
\text { creatinine) }\end{array}$ \\
\hline $1-2$ & 19 & $4.14+1.76$ & $1.33+0.91$ \\
$3-4$ & 27 & $6.50+3.83$ & $0.54+0.28$ \\
$5-6$ & 15 & $6.69+3.34$ & $0.47+0.22$ \\
$7-8$ & 19 & $7.45+3.48$ & $0.34+0.26^{\star}$ \\
$9-10$ & 17 & $11.30+3.67$ & $0.27+0.18$ \\
$11-12$ & 15 & $11.40+3.16$ & $0.29+0.15$ \\
$13-14$ & 11 & $12.64+7.64$ & $0.25+0.11$ \\
\hline
\end{tabular}

^Not Gaussian distribution.

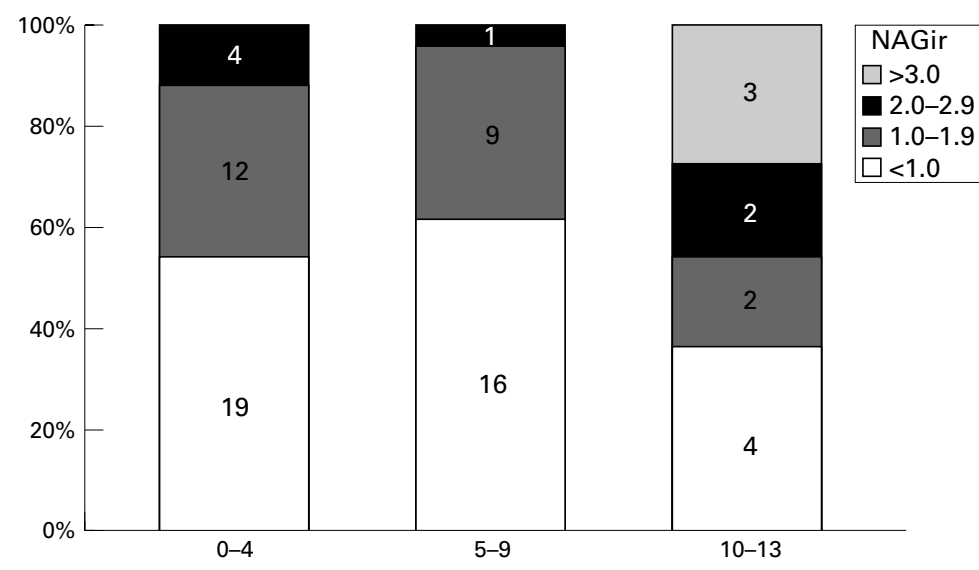

Duration of therapy (y)

Figure 1 Distribution of NAGir depending on duration of therapy.

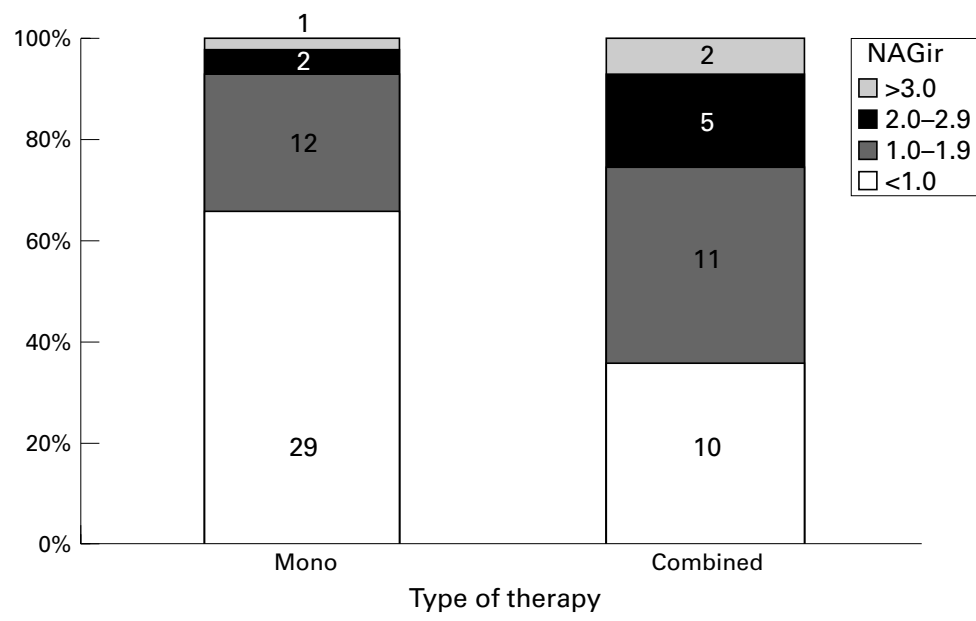

Figure 2 Distribution of NADir depending on type of therapy. standard deviations of healthy newborns and children have been published previously (table 4). ${ }^{1415}$

To compensate for the daily variation in urinary flow, NAGase activity was related to the creatinine concentration of the urine sample, and given as NAG index (NAGi) in $\mu \mathrm{mol} / \mathrm{min} / \mathrm{mmol}{ }^{1}$

Normal values of NAG indices are age dependent, and therefore findings can be compared only within limited age groups. To compare the results, a new index was introduced: the relative NAG index (NAGir). The NAG index value of each patient was divided by the upper limit of the normal range (mean +2 SD) of the appropriate age cohorts. A NAGir value of less than 1 represents normal conditions. A value greater than 1 indicates tubulopathy. NAGir of different groups were statistically analysed using variance analysis and the Welch test. The $\chi^{2}$ test was applied to compare the frequencies of abnormal NAGir values after different drugs or duration of therapy. ${ }^{16}$ Results are given as mean + SD. The ethical committee of our hospital authorised us to perform this study. Informed consent was given by the parents of the patients.

\section{Results}

We found that the distribution of the NAGir values of patients depended significantly on the length of therapy ( $p<0.001$, one way analysis of variance; fig 1). Thus duration of therapy alone affects the appearance and seriousness of tubulopathy. Table 2 summarises urinary NAGir values of children with epilepsy receiving monotherapy or combined therapy. We also found that NAGir values were significantly higher in the group receiving combined therapy $(1.52 \quad(+1.21) \quad v \quad 0.99 \quad(+0.73)$; $\mathrm{p}<0.05$, Welch's $d$ test; fig 2). The incidence of abnormal values was significantly higher ( $p<0.05, \chi^{2}$ test) in the group receiving combined therapy $(64 \%)$ than among those on monotherapy (34\%; table 2).

Grouping the patients according to the applied monotherapy, it was found that NAGir values were higher in those treated with valproic acid, than with carbamazepine (1.23 $(+0.95) v 0.79(+0.41)$ respectively), but the difference was not significant $(p>0.05$, Welch's $d$ test). In the combined therapy group, NAGir values did not depend on medication ( $p>0.1$, one way analysis of variance; table 3).

From the patients having raised serum AED concentrations:

- Two patients were on valproic acid monotherapy (serum concentration 12-13 $\mu \mathrm{g}$ / $\mathrm{ml}$ ); both had pathological NAGir (greater than 1)

- Five patients were on carbamazepine monotherapy (serum concentration 101$130 \mu \mathrm{g} / \mathrm{ml}$ ); three of them had pathological NAGir (greater than 1).

\section{Discussion}

Most patients with epilepsy receive long term treatment. Although the dosage of drugs is standardised, there may be great interindi- 
vidual differences in sensitivity to a specific agent. The narrower the gap between therapeutic and toxic effect, the more it is necessary to control blood concentrations of the medicine. Five of our seven patients with raised serum AED concentrations had pathological NAGir. This suggests a necessity for drug monitoring.

Anticonvulsant therapy can alter a variety of physiological functions. Although serum chemistry and urinalysis are often performed in children with epilepsy receiving anticonvulsant drugs in order to detect serum concentrations of AEDs, and occasional hepatorenal toxicity, the results are usually normal. This led to doubts as to whether urinalysis is reliable in detecting early renal changes, and whether or not it should be a routine examination in these patients.

The aim of our study was to detect these abnormalities, and also to determine whether such an effect arose from single or multiple drug usage. We measured urinary NAG during chronic anticonvulsant treatment of children with epilepsy. In accordance with previous results we found that the duration of treatment is associated with the development of nephrotoxicity. ${ }^{10-13}$

There were significant differences in the NAGir of patients depending on duration of therapy. That is, the length of treatment alone affects the NAGir. It was significantly higher in the combined than in the monotherapy group. More data are needed to prove that those on combined therapy for more than 10 years have an even higher NAGase excretion than others. We could not exclude the possibility that modified tubular function might be caused by renal tubular enzyme induction by AEDs.

Based on these findings, however, we suggest that combined therapy, and in certain cases also monotherapy longer than 10 years, results in a higher risk of tubular functional impairment. For this reason we suggest that tubular function should be monitored in patients on antiepileptic drugs. If pathological NAG indices are found, drug concentrations must be checked, and if necessary the dose of the drug should be altered.

1 Csáthy L, Pócsi I. Urinary N-acetyl- $\beta$-D-glucosaminidase determination in newborns and children: methods and determination in newborns and children: methods and diagnostic applicatio

2 Price RG. Urinary enzymes, nephrotoxicity and renal disease. Toxicology 1982;23:98-134

3 Kunin CM, Chesney RW, Craig WA, England AC, De Angelis C. Enzymuria as a marker of renal injury and disease: studies of $\mathrm{N}$-acetyl- $\beta-\mathrm{D}$-glucosaminidase in the general population and in patients with renal disease. Pediatrics 1978;64:751-60.

4 Watanabe K, Kojima K, Fukuda J, Ohbayasi K, Kobayashi $\mathrm{T}$, Iwase S. Reliability of urinary N-acetyl- $\beta$-Dglucosaminidase as an indicator of renal tubular damage in neonates. Biol Neonate 1987;52:16-21.

5 Lenoir GR, Perignon JL, Gubler MC, Broyer M. Valproic acid: a possible cause of proximal tubular renal syndrome. acid: a possible cause of

6 Lin CY, Chiang H. Sodium valproate induced interstitial nephritis. Nephron 1988;48:43-6.

7 Hogg RJ, Sawyer M, Hecox K, Eigenbrodt E. Carbamazepine induces acute tubulointestinal nepritis. $f$ Pediatr 1981;98:830-2

8 Ray-Chaudhuri K, Pye IF, Boggild M. Hypersensitivity to carbamazepine presenting with a leukemoid reaction, eosinophilia, erythroderma, and renal failure. Neurology 1989;39:436-8.

9 Silvermann SH, Gribetz D, Rausen AR. Neprotic syndrome associated with ethosuximide. Am F Dis Child 1978;132: 99-101

10 Novo MLP, Izumi T, Yokota K, Fukuyama Y. Urinary excretion of $\mathrm{N}$-acetyl- $\beta$-D-glucosaminidase by patients with epilepsy. Brain Dev 1993;15:157-60.

11 Otsuka T, Sunaga Y, Hikima A. Urinary N-acetyl- $\beta-D-$ glucosaminidase and guanidinoacetic acid levels in epileptic patients treated with anti-epileptic drugs. Brain Dev 1994;16:437-40.

12 Tseng CL, Wang PJ, Tsau YK, Lin MY, Shen YZ. Urinary of N-acetyl- $\beta$-glucosaminidase (NAG) in children receiving antiepileptic drugs. Acta Paediatr Sin 1992;33:251-6.

13 Yüksel $A$, Cengiz M, Seven $M$, Cengiz S, Cenani A. $\mathrm{N}$-acetyl- $\beta$-glucosaminidase and $\beta$-galactosidase in children receiving antiepileptic drugs. Paediatr Neurol 1999;20: 24-6.

14 Pócsi I, Csáthy L, Oláh AV, Price RG. Assay of N-acetyl- $\beta$ $\mathrm{D}$-glucosaminidase in neonate urine: comparison of two new colorimetric methods using "MNP-GlcNAc" and "VRA-GlcNAc" as substrates. Ann Clin Biochem 1992;29: $292-5$.

15 Oláh AV, Csáthy L, Pócsi I, Price RG. Reference ranges for urinary $\mathrm{N}$-acetyl- $\beta$-D-glucosaminidase (NAG) in healthy urinary $N$-acetyl- $\beta$-D-glucosaminidase (NAG) in healthy children determined with three colorimetric methods using PNP-GlcNAc MNP-GlcNAc and VRA-C

16 Armitage P. Statistical methods in medical research. Oxford: Blackwell Science Publishers, 1971. 